\title{
Chemical Composition and Antibacterial Activity of Essential Oils of Two Species of Lamiaceae against Phytopathogenic Bacteria
}

\author{
ARZU GORMEZ1', SEDAT BOZARI², DERYA YANMIS ${ }^{3 \star}$, MEDINE GULLUCE², \\ FIKRETTIN SAHIN ${ }^{5}$ and GULERAY AGAR ${ }^{4}$
}

\begin{abstract}
${ }^{1}$ Department of Molecular Biology and Genetics, Faculty of Science, Erzurum Technical University, Erzurum, Turkey
${ }^{2}$ Department of Biology, Faculty of Arts and Science, Mus Alparslan University, Mus, Turkey

${ }^{3}$ Department of Biology, Faculty of Science, Ataturk University, Erzurum, Turkey

${ }^{4}$ Department of Medicinal and Aromatic Plants, Espiye Vocational School, Giresun University, Giresun, Turkey

${ }^{5}$ Department of Genetics and Bioengineering, Faculty of Engineering and Architecture, Yeditepe University, Kayisdagi, Istanbul, Turkey
\end{abstract}

Submitted 25 June 2012, revised 29 March 2015, accepted 8 April 2015

Abstract

In this study, we aimed to determine chemical composition and antibacterial activities of Satureja hortensis and Calamintha nepeta against to 20 phytopathogenic bacteria causing serious crop loss. The essential oils of S. hortensis and C. nepeta were isolated by the hydrodistillation method and the chemical composition of the essential oils were analyzed by GC-MS. The antibacterial properties of the essential oils were evaluated against 20 phytopathogenic bacteria through Disc diffusion assay and micro dilution assay. The results revealed that the essential oils of S. hortensis and C. nepeta have significant antibacterial activity. Furthermore, the findings of the study are valuable for future investigations focusing on the alternative natural compounds to control plant diseases.

Ke y words: Calamintha nepeta, Satureja hortensis, antibacterial activity, biopesticide, chemical composition

\section{Introduction}

In recent years, one of the most popular subjects is the increase of yield production because of starvation that threats millions of people (Fletcher et al., 2006). Every year, substantial part of the yield has been lost due to plant diseases caused by fungi, bacteria and viruses. Bacteria can also cause undesirable effects on quality, reliability and preservation of crop. To solve these problems, synthetic chemicals have been mostly used for many years. However, due to indiscriminate use of antimicrobial synthetic chemicals in the treatment of infectious diseases, both human and plant pathogenic microorganisms have developed resistance to multiple drugs/chemical substances (Sahin et al., 2003; Gormez et al., 2012). In addition, these chemical compounds can cause undesirable effects on environment because of their slow biodegradation and several serious side effects on mammalian health because of toxic residues in agricultural products (McManus et al., 2002; Horvath et al., 2009; Kotan et al., 2010). This situation forced the researchers to discover new natural antimicrobial substances from various sources like medicinal plants (Clark, 1996; Cordell, 2000). Among many plant products, essential oils are the most studied plant secondary metabolites. Essential oils such as biopesticide have some advantages, where pathogenic microorganisms are not likely to develop resistance against them, little or no mammalian toxicity and not accumulated in soils (Heisey and Heisey, 2003; Singh et al., 2003, 2005; Cardile et al., 2009; Grosso et al., 2010; Tian et al., 2011). Therefore, the present study was conducted to investigate alternative antimicrobial agents among essential oils of Lamiaceae species that can be used as biopesticide.

The Lamiaceae is a family of plants having about 233 genera and 6900 species (Heywood et al., 2007). The phenolic compounds, such as rosmarinic acid, caffeic acid, ferulic acid, chlorogenic acid, luteolin, apigenin, genkwanin, quercitrin, rutin, epicatechin and catechin are rich in Lamiaceae (Moreno et al., 2006; Ben Farhat et al., 2009; Castro-Vazquez et al., 2009). Due to its rich contents of plants, they have many biological activities, such as anti-inflammatory, anticancer, antifungal,

\footnotetext{
* Corresponding author: Yanmis D., Department of Medicinal and Aromatic Plants, Espiye Vocational School, Giresun University, Giresun, Turkey; e-mail: deryayanmis@yahoo.com
} 
antimicrobial activity (Sarer and Pancali, 1998; Cheung and Tai, 2007; Figueiredo et al., 2008; Takaki et al., 2008; Quave et al., 2008). C. nepeta and S. hortensis are well known aromatic and medicinal plants which belong to Lamiaceae. They have been used in folk medicines to treat many illnesses because of their antispasmodic, expectorant, diuretic, antimicrobial activities as it is stated in the relevant literature (Sarer and Pancali, 1998; Baser et al., 2000; Sahin et al., 2003). However, there is no report concerning the antibacterial activity of these essential oils against these many phytopathogenic bacteria.

In the study, we aimed to determine chemical compositions of hydro-distilled essential oils of S. hortensis and C. nepeta by GC-MS system as their biological activities were connected to their chemical compositions and to evaluate their antibacterial potentials against plant pathogen bacteria which have not been evaluated in the previous studies.

\section{Experimental}

\section{Materials and Methods}

Plant materials. C. nepeta and S. hortensis were collected at the flowering stage in July 2010, from the eastern part of Erzurum in Turkey. Identification of the plant materials was confirmed by a plant taxonomist, Assoc. Prof. Dr. Ozkan AKSAKAL, in the Department of Biology, Ataturk University, Erzurum, Turkey. Plants herbarium samples were stored in the herbarium of the Science Faculty, Ataturk University, Erzurum.

Isolation of the Essential Oils. Plant samples were dried in a canopy room. The aerial parts (leaves, flowers and steams) of the plants were powdered with blender and then subjected to water distillation for $2-3 \mathrm{~h}$ in a Clevenger-type apparatus (Thermal Laboratory Equipment, Turkey). The essential oils were stored at $+4^{\circ} \mathrm{C}$ for further studies.

GC-MS Analysis Conditions. The essential oils were analyzed by using a Thermofinnigan Trace GC/Trace DSQ/A1300, (E.I Quadrapole) equipped with a SGEBPX5 MS capillary column $(30 \mathrm{~m}$ X $0.25 \mathrm{~mm}$ i.d., $0.25 \mu \mathrm{m})$. For GC-MS detection, an electron ionization system with ionization energy of $70 \mathrm{eV}$ was used. Helium was the carrier gas at a flow rate of $1 \mathrm{ml} / \mathrm{min}$. Injector and MS transfer line temperatures were set at $220^{\circ} \mathrm{C}$ and $290^{\circ} \mathrm{C}$, respectively. The program was used at $50-150^{\circ} \mathrm{C}$ at a rate of $3^{\circ} \mathrm{C} / \mathrm{min}$. Diluted samples $(1 / 100$, $\mathrm{v} / \mathrm{v}$, in methylene chloride) of $1.0 \mu$ were injected manually and in the splitless mode. The components were identified based on the comparison of their relative retention time and mass spectra with those of standards, Wiley $7 \mathrm{~N}$ library data of the GC-MS system and
Table I

Plant pathogenic bacterial species used in the study

\begin{tabular}{|l|l|l|}
\hline \multicolumn{1}{|c|}{ Bacteria } & Strain No & \multicolumn{1}{c|}{ Host } \\
\hline Agrobacterium tumefaciens & Apricot & AA-685 \\
\hline Bacillus pumilus & Apricot & AA-479 \\
\hline $\begin{array}{l}\text { Clavibacter michiganensis subsp. } \\
\text { michiganensis }\end{array}$ & Tomato & AA-703 \\
\hline Enterobacter intermedius & Cherry & AA-184 \\
\hline Erwinia caratovora subsp. caratovora & Tomato & AA-687 \\
\hline Erwinia chrysanthemi & Apricot & AA-58 \\
\hline Pseudomonas cichorii & Peach & AA-234 \\
\hline Pseudomonas corrugate & Tomato & AA-684 \\
\hline Pseudomonas fluorescens & Apricot & AA-616 \\
\hline Pseudomonas syringae pv. syringae & Cherry & AA-218 \\
\hline Pseudomonas syringae pv. syringae & Apricot & AA-637 \\
\hline Pseudomonas syringae pv. syringae & Apricot & AA-638 \\
\hline Pseudomonas syringae pv. syringae & Apricot & AA-647 \\
\hline Pseudomonas syringae pv. phaseolicola & Beans & AA-652 \\
\hline Pseudomonas syringae pv. pisi & Peach & AA-237 \\
\hline Pseudomonas syringae pv. tabaci & Apricot & AA-704 \\
\hline Pseudomonas syringae pv. tomato & Cherry & AA-220 \\
\hline Ralstonia solanacearum & Apricot & AA-116 \\
\hline Xanthomonas axonopodis pv. campestris & Pepper & AA-705 \\
\hline Xanthomonas vesicatoria & Tomato & AA-683 \\
\hline
\end{tabular}

literature data. The results were also confirmed by the comparison of the compounds elution order with their relative retention indices on non-polar phases reported in the literature.

Plant pathogenic bacterial strains. The essential oils of the plants were tested against 20 plant pathogenic bacterial strains which were shown in the Table I. All the bacterial strains were isolated from some fruits and vegetables exhibiting typical bacterial disease symptoms on their respective host plants. They were identified by using conventional methods such as morphological, biochemical, pathogenicity tests and microbial identification system (MIS) (Miller and Berger, 1985). The isolated and identified bacterial cultures were preserved in Luria broth and 30\% glycerol solutions at $-80^{\circ} \mathrm{C}$ prior to use.

Antimicrobial activity: 2 Disc diffusion assay. Twofold serial dilutions of the essential oils were made by diluting \%10 DMSO to prepare a decreasing concentration range from $500 \mu \mathrm{g} / \mathrm{ml}$ to $7.81 \mu \mathrm{g} / \mathrm{ml}$. Antimicrobial tests were carried out by disc diffusion assay using $100 \mu \mathrm{l}$ of suspension containing $10^{8} \mathrm{cfu} / \mathrm{ml}$ of bacteria spread on tryptic soy agar (TSA) medium by a sterile swab (Murray et al., 1995). The discs (6 mm in diameter) were individually impregnated with $10 \mu$ lof essential oils at all the prepared concentrations and placed on the inoculated agar. Negative controls were prepared using the same solvents employed to dilute the essen- 
Table II

Antibacterial activities of the essential oils of S. hortensis and C. nepeta

\begin{tabular}{|c|c|c|c|c|c|c|c|c|}
\hline \multirow{3}{*}{ Bacteria } & \multicolumn{3}{|c|}{ S. hortensis } & \multicolumn{3}{|c|}{ C. nepeta } & \multirow{3}{*}{\begin{tabular}{c|}
$\begin{array}{c}\text { Negative } \\
\text { control }\end{array}$ \\
DMSO
\end{tabular}} & \multirow{3}{*}{\begin{tabular}{|c} 
Positive control \\
Standart \\
antibiotic discs
\end{tabular}} \\
\hline & \multicolumn{2}{|c|}{$\mathrm{DD}$} & \multirow{2}{*}{ MIC } & \multicolumn{2}{|c|}{$\mathrm{DD}$} & \multirow{2}{*}{ MIC } & & \\
\hline & $500 \mu \mathrm{g}$ & $7.81 \mu \mathrm{g}$ & & $500 \mu \mathrm{g}$ & $7.81 \mu \mathrm{g}$ & & & \\
\hline Agrobacterium tumefaciens & 48 & 8 & 7.81 & 48 & 8 & 7.81 & - & 28 (SCF) \\
\hline Bacillus pumilus & 47 & 7 & 7.81 & 47 & 7 & 7.81 & - & 23 (OFX) \\
\hline Clavibacter michiganensis ssp. michiganensis & 48 & 9 & 7.81 & 48 & 8 & 7.81 & - & 26 (SCF) \\
\hline Enterobacter intermedius & 16 & 8 & 7.81 & 35 & 7 & 7.81 & - & 26 (SCF) \\
\hline Erwinia caratovora ssp. caratovora & 48 & 9 & 7.81 & 45 & 7 & 7.81 & - & 29 (OFX) \\
\hline Erwinia chrysanthemi & 48 & 8 & 7.81 & 46 & 8 & 7.81 & - & 25 (SCF) \\
\hline Pseudomonas cichorii & 10 & - & 31.25 & 36 & 8 & 7.81 & - & 25 (OFX) \\
\hline Pseudomonas corrugate & 48 & 10 & 7.81 & 48 & 7 & 7.81 & - & 26 (OFX) \\
\hline Pseudomonas fluorescens & 48 & 7 & 7.81 & 43 & 8 & 7.81 & - & 11 (OFX) \\
\hline Pseudomonas syringae pv. syringae ${ }^{* * *}$ & 48 & 9 & 7.81 & 48 & 8 & 7.81 & - & 25 (OFX) \\
\hline Pseudomonas syringae pv. syringae & 8 & - & 31.25 & 33 & 8 & 7.81 & - & $21(\mathrm{OFX})$ \\
\hline Pseudomonas syringae pv. syringae & 8 & - & 31.25 & 39 & 8 & 7.81 & - & 20 (OFX) \\
\hline Pseudomonas syringae pv. syringae & 8 & - & 31.25 & 42 & 10 & 7.81 & - & $21(\mathrm{OFX})$ \\
\hline Pseudomonas syringae pv. phaseolicola & 14 & - & 15.63 & 44 & 7 & 7.81 & - & 24 (OFX) \\
\hline Pseudomonas syringae pv. pisi & 14 & - & 15.63 & 41 & 8 & 7.81 & - & 24 (OFX) \\
\hline Pseudomonas syringae pv. tabaci & 10 & - & 31.25 & 45 & 9 & 7.81 & - & 23 (OFX) \\
\hline Pseudomonas syringae pv. tomato & 11 & 8 & 7.81 & 45 & 8 & 7.81 & - & 25 (OFX) \\
\hline Ralstonia solanacearum & 48 & 10 & 7.81 & 48 & 8 & 7.81 & - & $24(\mathrm{SCF})$ \\
\hline Xanthomonas axonopodis pv. campestris & 48 & - & 31.25 & 47 & 10 & 7.81 & - & 23 (SCF) \\
\hline Xanthomonas vesicatoria & 47 & 7 & 7.81 & 47 & 8 & 7.81 & - & 21 (SCF) \\
\hline
\end{tabular}

DD, Inhibition zone in diameter ( $\mathrm{mm} /$ sensitive strains) around the disks $(6 \mathrm{~mm})$; MIC, minimal inhibitory concentration; * DMSO; Dimethyl sulfoxide (\%10); ${ }^{\star *}$ OFX, ofloxacin $(10 \mu \mathrm{g} /$ disc $)$; SCF, sulbactam $(30 \mu \mathrm{g} /$ disc $)+$ cefoperazone $(75 \mu \mathrm{g})(105 \mu \mathrm{g} /$ disc $)$ were used as positive reference standart antibiotic discs (oxoid); ${ }^{* *}$ from different host (cherry).

tial oils. Positive controls were prepared using the antibiotics as indicated in Table II. The bacterial cultures were incubated at $27^{\circ} \mathrm{C}$ for $48 \mathrm{~h}$. Antimicrobial activities of the essential oils were evaluated by measuring the zone of inhibition against the bacteria. Each test assays were repeated in triplicate.

Micro dilution assay. The minimal inhibition concentration (MIC) values studied for the bacteria were determined as sensitive to the essential oils in disc diffusion assay. The inocula of the bacteria were prepared from $12 \mathrm{~h}$ broth cultures and cultures were adjusted to $0.5 \mathrm{McF}$ arland Standard turbidity. The essential oils were prepared by diluting 10\% DMSO to prepare a decreasing concentration range from $500 \mu \mathrm{g} / \mathrm{ml}$ to $7.81 \mu \mathrm{g} / \mathrm{ml}$ to be tested in $10 \mathrm{ml}$ sterile test tubes containing tryptic soy broth. MIC values of the essential oils against bacterial strains were determined based on a micro-well dilution method (Zgoda and Porter, 2001). The 96-well plates were prepared by dispensing into each well $95 \mu \mathrm{l}$ of tryptic soy broth and $5 \mu \mathrm{l}$ of the inoculum. Then $100 \mu \mathrm{l}$ from essential oils from all the prepared concentrations were individually added into the wells. A negative control was prepared as the last well containing $195 \mu \mathrm{l}$ tryptic soy broth without essential oil and $5 \mu \mathrm{l}$ of the inoculum. Maxipime (Bristol-Myers Squibb) at the concentration range of $500-7.81 \mu \mathrm{g} / \mu \mathrm{l}$ was prepared in tryptic soy broth and used as standard drug for positive control. The plate was covered with a sterile plate sealer, mixed on plate shaker at $300 \mathrm{rpm}$ for $20 \mathrm{~s}$, and then incubated at $27^{\circ} \mathrm{C}$ for $24 \mathrm{~h}$. Bacterial growth was determined by absorbance at $600 \mathrm{~nm}$ using the $\mathrm{EL} \times 800$ universal microplate reader and confirmed by plating $5 \mu \mathrm{l}$ samples from clear wells on tryptic agar medium. The essential oils were tested against all the bacteria for three times. The MIC was defined as the lowest concentration of the compounds to inhibit the growth of microorganisms.

\section{Results and Discussion}

Chemical composition of the essential oils. The essential oil compositions of Turkish Satureja, Calamintha and the relative amounts of the components are shown in the Table III. This table shows that the Turkish Satureja contains carvacrol (79.17\%), $\gamma$-terpinene $(9.05 \%)$, p-cymene $(3.14 \%)$, thymol acetate (2.24\%), $\beta$-caryophyllene (1.48\%); Calamintha contains 
Table III

Essential oil contents of S. hortensis and C. nepeta

\begin{tabular}{|c|c|c|c|c|c|c|c|}
\hline \multirow{2}{*}{$\mathrm{RI}^{*}$} & \multicolumn{3}{|c|}{ S. hortensis } & \multicolumn{3}{|c|}{ C. nepeta } & \multirow{2}{*}{$\begin{array}{c}\text { Identification } \\
\text { methods }\end{array}$} \\
\hline & $\mathrm{RT}^{* *}$ & Components & (\%) & RT & Components & (\%) & \\
\hline 983 & 11.84 & $\beta$-Pinene & 0.33 & - & - & - & GC, MS, RI \\
\hline 995 & - & - & - & 13.21 & 3-Octanol & 0.70 & GC, MS, RI \\
\hline 1023 & 13.75 & $\alpha$-Terpinene & 0.55 & - & - & - & GC, MS, RI \\
\hline 1034 & 14.24 & p-Cymene & 3.14 & - & - & - & GC, MS, RI \\
\hline 1037 & - & - & - & 14.29 & Limonene & 13.51 & GC, MS, RI \\
\hline 1067 & 15.72 & $\gamma$-Terpinene & 9.05 & - & - & - & GC, MS, RI \\
\hline 1106 & - & - & - & 18.07 & Linalool & 0.51 & GC, MS, RI \\
\hline 1172 & 21.61 & Borneol & 0.64 & 21.59 & Borneol & 0.14 & GC, MS, RI \\
\hline 1178 & 21.99 & Terpinen-4-ol & 0.96 & 21.87 & Terpinen-4-ol & 4.55 & GC, MS, RI \\
\hline 1190 & - & - & - & 22.82 & a-Terpineol & 0.38 & GC, MS, RI \\
\hline 1255 & - & - & - & 25.65 & cis-Piperitone epoxide & 48.66 & GC, MS, RI \\
\hline 1289 & 26.97 & Thymol & 0.10 & - & - & - & GC, MS, RI \\
\hline 1296 & 27.43 & Carvacrol & 79.17 & 27.46 & Carvacrol & 2.13 & GC, MS, RI \\
\hline 1313 & - & - & - & 28.33 & Dihydrocarveol acetate & 1.24 & GC, MS, RI \\
\hline 1347 & 29.39 & Thymol acetate & 2.24 & - & - & - & GC, MS, RI \\
\hline 1369 & - & - & - & 30.43 & Piperitenone oxide & 22.08 & GC, MS, RI \\
\hline 1419 & 32.25 & $\beta$-Caryophyllene & 1.48 & 32.24 & $\beta$-Caryophyllene & 2.21 & GC, MS, RI \\
\hline 1442 & 33.04 & Aromadendrene & 0.30 & - & - & - & GC, MS, RI \\
\hline 1478 & 34.60 & $\gamma$-Muurolene & 0.25 & - & - & - & MS, RI \\
\hline 1486 & - & - & - & 34.87 & Germacrene D & 0.42 & GC, MS, RI \\
\hline 1494 & 35.24 & Viridiflorene & 0.35 & - & - & - & GC, MS, RI \\
\hline 1513 & 36.33 & $\gamma$-Cadinene & 0.51 & - & - & - & MS, RI \\
\hline 1574 & 39.40 & Spathulenol & 0.92 & - & - & - & MS, RI \\
\hline 1579 & - & - & - & 39.59 & Caryophyllene oxide & 0.80 & GC, MS, RI \\
\hline
\end{tabular}

$\mathbf{R I}^{\star}$; Retention index relative to $n$-alkanes on SGE-BPX5 capillary column, $\mathbf{R T}^{\star *}$; retention times, GC; identification was based on retention times of authentic compounds on SGE-BPX5 capillary column, MS; tentatively identified based on computer matching of the mass spectra of peaks with Wiley $7 \mathrm{~N}$ and TRLIB libraries and published data, RI; identification was based on comparison of retention index with those of published data

cispiperitone epoxide (48.66\%), piperitenone oxide (22.08), limonene (13.51\%) and terpinen-4-ol (4.55\%) as major components.

According to the previous studies, essential oil compositions of S. hortensis and C. nepeta from different origins showed varieties in terms of quality and quantity. The compositions of essential oils of S. hortensis were reported as $\gamma$-terpinene $(40.9 \%)$ and carvacrol (39.3\%) with $4.46 \%$ oil content by Gora et al. (1996); carvacrol $(40-49 \%)$ and $\gamma$-terpinene $(36-45 \%)$ by Svoboda (2003); carvacrol (46\%), $\gamma$-terpinene (37.7\%) and oil content of $0.93 \%$ by Sefidkon et al. (2006); carvacrol $(42.0-83.3 \%), \quad \gamma$-terpinene $(0.5-28.5 \%)$ and $p$-cymene $(1.0-17.1 \%)$ with twenty nine components in the oils by Hadiana et al. (2010); $\gamma$-terpinene (35.5\%), thymol (18.2\%) and carvacrol (29.7\%) from extracted oil through supercritical fluid extraction by Khajeh (2011). It can be concluded from all the previous studies that carvacrol, thymol, and their precursors, $p$-cymene and $\gamma$-terpinene are major components of
S. hortensis oil. Carvacrol and thymol were determined as the major components in all Satureja from Turkey, too. The compositions of essential oils of S. hortensis from Turkey were reported: thymol (29.0\%), carvacrol (26.5\%), a total 22 constituents consisted of $\gamma$-terpinene (22.6\%), and $p$-cymene (9.3\%) by Gulluce et al. (2003); carvacrol (42.0-63.0\%) with oil content ranged from $1.30 \%$ to $2.67 \%$ by Baser et al. (2004); p-cymene ( $40.6 \%$ and $35.9 \%$ ), thymol (39.9\% and $43.4 \%)$, carvacrol (5.7\% and $16.0 \%)$ and $\gamma$-terpinene $(3.7 \%$ and $3.2 \%)$ with oil content of $0.5 \%$ and $0.7 \%$ by Azaz et al. (2005); thymol (40.54\%), $\gamma$-terpinene (18.56\%), carvacrol (13.98\%), and $p$-cymene (8.97\%) by Adiguzel et al. (2007).

The main constituents of C. nepeta oils were determined in the previous studies as pulegone (about 50\%); menthone (9.4\%), limonene (7.0\%), menthol (4.6\%), piperitenone oxide (4.6\%), piperitone oxide (3.9\%), and piperitenone (3.4\%) by Flamini et al. (1999); pulegone (41.0\%), menthone $(32.0 \%)$, piperitone $(7.3 \%)$ and piperitenone (7.0\%) by Couladis and Tzakou (2001); 
pulegone $(75.5 \%)$, piperitenone oxide $(6.0 \%)$, menthone (5.3\%) and menthol (4.3\%) by Kitic et al. (2005); pulegone (76.5\%) and piperitone (6.1\%) by Schulz et al. (2005); pulegone, piperitenone oxide and piperitenone by Marongiu et al. (2010). According to previous studies, the essential oils of S. hortensis and C. nepeta contain similar major compounds in spite of differences in their quantity. These differences might have been derived from local, climatic, seasonal and experimental factors. Our results have generally confirmed the findings of the previous studies.

Antibacterial activities of essential oils. In this study, the essential oils at 7.81-500 $\mu \mathrm{g} /$ disk concentrations were also tested for antibacterial activities against 20 phytopathogenic bacterial strains isolated from fruit and vegetables origins (Table II). The inhibition zone above $7 \mathrm{~mm}$ in diameter was regarded as positive result. As shown in this table, the oils of S. hortensis and C. nepeta exhibited considerable antibacterial activities against most of the tested bacteria (7-48 $\mathrm{mm}$ inhibition zone). Both gram-positive and Gram-negative bacteria were sensitive to the tested essential oils. No significant difference in susceptibility was found between Gram-negative and Gram-positive bacteria. It was interesting to find that most of the essential oils had stronger MIC values than standard antibiotic. 10\% DMSO was used as a negative control, it exhibited no inhibition zone (Table II).

In various studies, although the extracts or essential oils of S. hortensis and C. nepeta were tested for their antimicrobial activity, there are no satisfactory reports against plant pathogenic bacteria. There is only a few data about the antibacterial effectiveness of the essential oil of S. hortensis against to phytopathogenic bacteria, which were provided by Gulluce etal. (2003), Sahin et al. (2003), Kizil and Uyar (2006), Kotan et al. (2007), Mihajilov-Krstev et al. (2009). The findings of those studies are supported by our findings demonstrating strong antimicrobial activity of essential oil of S. hortensis. To our knowledge, there is no report about the antibacterial properties of essential oil of C. nepeta against phytopathogenic bacterial strains. So, this study is the first report on the antibacterial effectiveness of the essential oil of C. nepeta against phytopathogenic bacteria.

According to our results the antibacterial effect of oil of $S$. hortensis was found to be lower than the essential oil of C. nepeta according to inhibition zone. But, generally, it is clear that both of the essential oils have strong antibacterial activity against tested phytopathogenic bacteria. Furthermore, in our study, we detected bactericidal activity against the tested bacteria, especially at high concentrations of essential oil of SH. In our study, generally most of the tested organisms were also sensitive to many of the essential oils. The maximal inhi- bition zones and MIC values of S. hortensis, C. nepeta showed a significant difference in the range of $7-48 \mathrm{~mm}$ and $7.81-31.25,7.81 \mu \mathrm{g} / \mathrm{ml}$, respectively (Table II). A.tumefaciens, B.pumilus, C.michiganensis subsp. michiganensis, E. intermedius, E. chrysanthemi, P. fluorescens, P. syringae pv. syringae (from cherry), P. syringae pv. tomato, $R$. solanacearum and $X$. vesicatoria were the most sensitive organisms against to both of essential oils (MIC value $7.81 \mu \mathrm{g} / \mathrm{ml}$ ). P. cichorii, P. syringae pv. syringae (isolated from apricot), P. syringae pv. tabaci and $X$. axonopodis pv. campestris were the most resistant microorganisms to the essential oil of $S$. hortensis with the MIC value $(31.25 \mu \mathrm{g} / \mathrm{ml})$. The other resistant microorganisms to essential oil of S. hortensis were P. syringae pv. phaseolicola and P. syringae pv. pisi $(15.63 \mu \mathrm{g} / \mathrm{ml})$. It is thought that the sensivity can be caused by the differences in host, virulent of pathogens, toxins produced by these pathogens. For example, although P. syringae pv. syringae isolated from cherry was determined as sensitive $(7.81 \mu \mathrm{g} / \mathrm{ml})$, P. syringae pv. syringae isolated from apricot was the most resistant microorganism to S. hortensis oil with MIC value $(31.25 \mu \mathrm{g} / \mathrm{ml})$. As shown in the Table II, C. nepeta showed promising inhibitory activity especially even at low concentration. All of the tested bacteria were sensitive against to the essential oil of C. nepeta, too.

According to these results, it is clear that the essential oils have a potential antibacterial effect on the tested bacteria. Many of the previous studies demonstrated that essential oils show a considerable antimicrobial activity due to the presence of chemical compounds containing mainly aromatic oxygenated monoterpenes and high phenolic contents; carvacrol, thymol, ketones, pulegone, piperitone and piperitenone. For example, the antimicrobial activity of the essential oil of C. nepeta can be explained with the high contents of ketones, pulegone, piperitone and piperitenone (Panizzi et al., 1993). This claim is further supported by our findings (Table III). Therefore, in our study; a high antibacterial effect of essential oil of $C$. nepeta can be associated with the presence of many components. In addition, according to studies made very recently, the antibacterial effect against the microorganisms were associated with the main constituents of the oil. According to Flamini et al. (1999), pulegone among constituents of C. nepeta only showed antimicrobial activity. It is also reported that some components such as carvacrol and thymol have potentials for controlling certain important plant pathogenic bacteria and seed disinfectant (Kotan et al., 2007, 2010). So, the high antimicrobial activity of $S$. hortensis essential oil could be explained through the high level of carvacrol, well known for having antibacterial activity; $C$. nepeta have cis-piperitone epoxide, piperitenone oxide. Furthermore, the synergistic and antagonistic effects of these chemicals and 
minor components can also affect the antibacterial activity of essential oils. In this regard, it is very important to stimulate systemic resistance mechanisms of the plants through the natural stimulators, use of healthy seeds, and seed disinfection through natural antimicrobial substances. Therefore, it is necessary to test several different combinations in commercial formulations of volatile oils and extracts and to determine bio-formulations according to the results obtained from these tests. It showed that essential oils of these plants are more effective than the antibiotics produced commercially against many bacteria. So; these essential oils are alternative components for defeating plant diseases. High level of antimicrobial activity of certain species in the Eastern Anatolia Region in Turkey put forward the necessity to take their gene sources under control and to research the possibility to cultivate them before dying out. Furthermore, it is necessary to carry out serious studies on their cultivatability.

In conclusion, the development of natural antimicrobials will help to decrease the negative effects (residues, resistance, and environmental pollution) of synthetic drugs. In this respect, natural antimicrobials may be also effective, selective, biodegradable, and less toxic to environment. In conclusion, according to the results presented in this study, we suggest that the essential oil of these plants can be used as antimicrobial agents in the management of plant diseases. However, the safety and toxicity of these compounds will need to be addressed.

\section{Literature}

Adiguzel A., H. Ozer, H. Kilic and B. Cetin. 2007. Screening of antimicrobial activity of essential oil and methanol extract of Satureja hortensis on foodborne bacteria and fungi. Czech J. Food Sci. $25,81-89$.

Azaz A.D., M. Kurkcuoglu, F. Satil, K.H.C. Baser and G. Tumen. 2005. In vitro antimicrobial activity and chemical composition of some Satureja essential oils. Flavour Fragr. J. 20: 587-591.

Baser K.H.C., N. Kirimer, M. Kurkcuoglu and B. Demirci. 2000 Essential Oils of Nepeta Species Growing In Turkey. Chem. Nat. Comp. 36: 356-359.

Baser K.H.C., T. Ozek, N. Kirimer and G.A. Tumen. 2004. Comparative study of the essential oils of wild and cultivated Satureja hortensis L. J. Essential Oil. Res. 9: 1-4.

Ben Farhat M., M.J. Jordan, R. Chaouech-Hamada, A. Landoulsi and J.A. Sotomayor. 2009. Variations in essential oil, phenolic compounds, and antioxidant activity of tunisian cultivated Salvia officinalis L. J. Agric. Food Chem. 57: 10349-10356.

Cardile V., A. Russo, C. Formisano, D. Rigano, F. Senatore, N.A. Arnold and F. Piozzi. 2009. Essential oils of Salvia bracteata and Salvia rubifolia from Lebanon: chemical composition, antimicrobial activity and inhibitory effect on human melanoma cells. J. Ethnopharmacol. 126: 265-272.

Castro-Vazquez L., M.C. Diaz-Maroto, M.A. Gonzalez-Vinas and M.S. Perez-Coello. 2009. Differentiation of monofloral citrus, rosemary, eucalyptus, lavender, thyme and heather honeys based on volatile composition and sensory descriptive analysis. Food Chem. 112: 1022-1030.
Cheung S. and J. Tai. 2007. Anti-proliferative and antioxidant properties of rosemary Rosmarinus officinalis. Oncol. Rep. 17: 1525-1531. Clark A.M. 1996. Natural products as resource for new drugs. Pharm. Res. 13: 1133-1141.

Cordell G.A. 2000. Biodiversity and drug discovery a symbiotic relationship. Phytochemistry 55, 463-480.

Couladis M. and O. Tzakou. 2001. Essential Oil of Calamintha nepeta subsp glandulosa from Greece. J. Essent. Oil Res. 13: 11-12. Figueiredo A.C., J.G. Barroso, L.G. Pedro, L. Salgueiro, M.G. Miguel and M.L. Faleiro. 2008. Portuguese Thymbra and Thymus species volatiles: Chemical composition and biological activities. Curr. Pharm. Design. 14: 3120-3140.

Flamini G., P.L. Cioni, R. Puleio, I. Morelli and L. Panizzi. 1999. Antimicrobial activity of the essential oil of Calamintha nepeta and its constituent pulegone against bacteria and fungi. Phytother Res. 13: 349-351.

Fletcher J., C. Bender, B. Budawle, W.T. Cobb, S.E. Gold, C.A. Ishimaru, D. Luster, U. Melcher, R. Murch, H. Scherm, R.C. Seen, J.L. Sherwood, B.W. Sobral and S.A. Tolin. 2006. Plant pathogen forensics: capabilities needs, and recommendations. Microbiol. Mol. Biol. Rev. 70: 450-471.

Gora J., A. Lis and A.L. Ewandowski. 1996. Chemical composition of the essential oil of cultivated Summer Savory (Satureja hortensis L. cv Saturn). J. Essent. Oil. Res. 8: 427-428.

Gormez A., Bozari S., Yanmis D., Gulluce M., Agar G. and Sahin F. 2012. Antibacterial activity and chemical composition of essential oil obtained from Nepeta nuda against phytopathogenic bacteria. J. Essent. Oil. Res. 25: 149-153.

Grosso C., J.A. Coelho, J.S. Urieta, A.M.F. Palavra and J.G. Barroso. 2010. Herbicidal activity of volatiles from coriander, winter savory, cotton lavender, and thyme isolated by hydrodistillation and supercritical fluid extraction. J. Agric. Food Chem. 58: 11007-11013. Gulluce M., M. Sokmen, D. Daferera, G. Agar, H. Ozkan, N. Kartal, M. Polissiou, A. Sokmen and F. Sahin. 2003. In vitro antibacterial, antifungal, and antioxidant activities of the essential oil and metanol extracts of herbal parts and callus cultures of Satureja hortensis L. J. Agric. Food Chem. 51: 3958-3965.

Hadiana J., S.N. Ebrahimi and P. Salehic. 2010. Variability of morphological and phytochemical characteristics among Satureja hortensis L. accessions of Iran. Ind. Crop. Prod. 32: 62-69.

Heisey R.M. and T.K. Heisey. 2003. Herbicidal effects under field conditions of Ailanthus altissima bark extract, which contains ailanthone. Plant Soil. 256: 85-99.

Heywood, V.H., R.K. Brummitt, A. Culham, and O. Seberg. 2007. Flowering plant families of the world. Kew Publishing: Royal Botanic Gardens.

Horvath G., K. Kovacs, B. Kocsis and I. Kustos. 2009. Effect of thyme (Thymus vulgaris L.) essential oil and its main constituents on the outer membrane protein composition of Erwinia strains studied with microfluid chip technology. Chromatographia 70, $1645-1650$

Khajeh M. 2011. Optimization of process variables for essential oil components from Satureja hortensis by supercritical fluid extraction using Box-Behnken experimental design. J. Supercrit Fluid 55: 944-948.

Kitic D., G. Stojanovic, R. Palic and V. Randjelovic. 2005. Chemical composition and microbial activity of the essential oil of Calamintha nepeta (L.) Savi ssp. nepeta var. subisodonda (Borb.) Hayek from Serbia. J. Essent. Oil. Res. 17: 701-703.

Kizil S. and F. Uyar. 2006. Antimicrobial activities of some thyme (Thymus, Satureja, Origanum and Thymbra) species against important plant pathogens. Asian J. Chem. 18: 1455-1461.

Kotan R., F. Dadasoglu, S. Kordali, A. Cakır, N. Dikbas and R. Cakmakc1. 2007. Antibacterial activity of essential oils extracted from some medical plants, carvacrol and thymol on Xanthomonas 
axonopodis pv. vesicatoria (Doidge) Dye causes bacterial spot disease on pepper and tomato. J. Agric. Techno. 3: 299-306.

Kotan R., A. Cakir, F. Dadasoglu, T. Aydin, R. Cakmakci, H. Ozer, S. Kordali, E. Mete and N. Dikbas. 2010. Antibacterial activities of essential oils and extracts of Turkish Achillea, Satureja and Thymus species against plant pathogenic bacteria. J. Sci. Food Agr. 90: $145-160$.

Marongiu B., A. Piras, S. Porcedda, D. Falconieri, A. Maxia, M.J. Gonçalves, C. Cavaleiro and L. Salgueiro. 2010. Chemical composition and biological assays of essential oils of Calamintha nepeta (L.) Savi subsp. nepeta (Lamiaceae). Nat. Prod. Res. 24, 1734-1742. McManus P.S., V.O. Stockwell, G.W. Sundin and A.L. Jones. 2002. Antibiotic use in plant agriculture. Annu. Rev. Phytopathol. 40, 443-465.

Mihajilov-Krstev T., D. Radnovic, D. Kitic, Z. Stojanovic-Radic and B. Zlatkovic. 2009. Antimicrobial activity of Satureja hortensis L. Essential oil against pathogenic microbial strains. Biotechnol. and Biotechnol. Eq. 23: 1492-1496.

Miller I. and T. Berger. 1985. Bacteria identification by gas chromatography of whole cell fatty acids. Hewlett-Packard Gas Chromatography Application Note Hewlett-Packard Co Alto CA 228-238. Moreno S., T. Scheyer, C.S. Romano and A.A. Vojnov. 2006. Antioxidant and antimicrobial activities of rosemary extracts linked to their polyphenol composition. Free Radical Res. 40: 223-231.

Murray P.R., E.J., Baron, M.A., Pfaller, F.C., Tenover and R.H. Yolke. 1995. Manual of Clinical Microbiology (eds) American Society for Microbiology, Washington, DC, 1482.

Panizzi L., G. Flamini, P.L. Cioni and I. Morelli. 1993. Composition and antimicrobial properties of essential oil of four Mediterranean Lamiaceae. J. Ethnopharmacol. 39: 167-170.

Quave C.L., L.R. Plano, T. Pantuso and B.C. Bennett. 2008. Effects of extracts from Italian medicinal plants on planktonic growth, biofilm formation and adherence of methicillin-resistant Staphylococcus aureus. J. Ethnopharmacol. 118: 418-428.
Sahin F., I. Karaman, M. Gulluce, H. Ogutcu, M. Sengul, A. Adiguzel, S. Oztürk and R. Kotan. 2003. Evaluation of antimicrobial activities of Satureja hortensis L. J. Ethnopharmacol. 87: 61-65.

Sarer E. and S.S. Pancali. 1998. Composition of the Essential Oil from Calamintha nepeta (L.) Savi ssp. glandulosa (Req.) P.W. Ball. Flavour and Frag J. 13: 31-32.

Schulz H., G. Ozkan, M. Baranska, H. Kruger and M. Ozcan. 2005. Characterisation of essential oil plants from Turkey by IR and Raman spectroscopy. Vib. Spectrosc. 39: 249-256.

Sefidkon F., K. Abbasi and G. Bakhshi. 2006. Influence of drying and extraction methods on yield and chemical composition of the essential oil of Satureja hortensis. Food Chem. 99: 19-23.

Singh H.P., D.R. Batish and R.K. Kohli. 2003. Allelopathic interactions and allelochemicals: new possibilities for sustainable weed management. Crit. Rev. Plant Sci. 22: 239-311.

Singh H.P., D.R. Batish, N. Setia and R.K. Kohli. 2005. Herbicidal activity of volatile oils from Eucalyptus citriodora against Parthenium hysterophorus. Ann. Appl. Biol. 146: 89-94.

Svoboda K.P. 2003. Investigation of volatile oil glands of Satureja hortensis L. (Summer Savory) and phytochemical composition of different varieties. Int. J. Aromath. 13: 196-202.

Takaki I., L.E. Bersani-Amado, A. Vendruscolo, S.M. Sartoretto, S.P. Diniz, C.A. Bersani-Amado and R.K. Cuman. 2008. Antiinflammatory and antinociceptive effects of Rosmarinus officinalis L. essential oil in experimental animal models. J. Med. Food 11: 741-746.

Tian J., X. Ban, H. Zeng, B. Huang, J. He and Y. Wang. 2011. In vitro and in vivo activity of essential oil from dill (Anethum graveolens L.) against fungal spoilage of cherry tomatoes, Food Control 22: 1992-1999.

Zgoda J.R. and J.R. Porter. 2001. A convenient micro dilution method for screening natural products against bacteria and fungi. Pharm. Biol. 39: 221-225. 
